\section{Note}

Data include previously published diatomderived sea-ice reconstruction (Crosta et al., 2004; www.sciencedirect.com/science/journal/03778398) and EPICA Dome C ssNa+ flux and D data (NOAA Paleoclimatology website www.ncdc.noaa.gov/paleo/paleo.html).

\section{References}

Abram, N., McConnell, J.R., Thomas, E.R., Mulvaney, R., Aristarain, A.J. 2008: Ice core records of 20th century sea ice decline in the Bellingshausen Sea, Geophysical Research Letters, submitted.

Abram, N., Mulvaney, R., Wolff, E.W., and Mudelsee, M., 2007: Ice core records as sea ice proxies: an evaluation from the Weddell Sea region of Antarctica, Journal Geophysical Research, 112: D15101, doi:15110.11029/12006JD008139.

Röthlisberger, R. et al., 2008: The southern hemisphere at glacial terminations: insights from the Dome C ice core, Climate of the Past:
Open Discussion, 4: 345-356. www.clim-past.net/4/345/2008/ cp-4-345-2008.html

Wolff, E.W. et al., 2006: Southern ocean sea-ice extent, productivity and iron flux over the past eight glacial cycles, Nature, 440: 491-496.

Wolff, E.W., Rankin, A.M., and Röthlisberger, R., 2003: An ice core indicator of Antarctic sea ice production?, Geophysical Research Letters, 30(22): 2158. doi:10.1029/2003GLL18454.

For full references please consult:

www.pages-igbp.org/products/newsletters/ref2009_1.html

\title{
Accurate chronology for Antarctic ice cores on orbital
} \section{timescales}

Kenju Kawamura

National Institute of Polar Research, Research Organization of Information and Systems, Tokyo, Japan; kawamura@nipr.ac.jp

An accurate chronology of Dome Fuji and Vostok ice core records, with dating accuracy better than 2 kyr, has been established for the past $\mathbf{4 0 0} \mathrm{kyr}$ and is consistent with the Milankovitch theory for the sequence of 100-kyr climatic cycles.

Deep ice cores from Antarctica have provided key records of past climate, including local temperature, atmospheric greenhouse gases and aerosols (e.g., Petit et al., 1999; Kawamura et al., 2007; Lüthi et al., 2008), over several glacial-interglacial cycles. In particular, the records have revealed a strong correlation between Antarctic temperature and greenhouse gas concentrations. In order to understand further the roles of both orbital and greenhouse gas forcings on climate changes, and to test Milankovitch forcing as the driver for the 100-kyr cycles seen in the ice core proxies, one would need paleoclimate chronologies with accuracy better than $\sim 2 \mathrm{kyr}(\sim 10 \%$ of a precession cycle). A brief review is presented here on recent progress in improving the chronology of Antarctic ice cores for $\sim 80 \mathrm{kyr}$ BP and older, by orbital tuning of the record of oxygen-to-nitrogen concentration ratio $\left(\mathrm{O}_{2} / \mathrm{N}_{2}\right)$ in trapped air with the local summertime insolation (Kawamura et al., 2007; Suwa and Bender, 2008). The implications for our understanding of the mechanisms of glacial cycles is also discussed.

\section{Orbital tuning using $\mathrm{O}_{2} / \mathrm{N}_{2}$}

Dating of the Antarctic deep ice cores involves models of past snow accumulation rates and ice flow (to account for thinning) whose parameters are constrained by depth-age control points with associated uncertainties (typically 2-6 kyr for MIS 5 and older periods). The error of the glaciological chronology may be large (>10 kyr) especially deeper in cores (> 2000 m, e.g., GT4 of Vostok and EDC2 of Dome C chronologies) because the real ice flow and/ or accumulation histories do not follow the models' simple assumptions. Orbital tuning utilizes the known relationship between a measured parameter in the ice and an insolation curve to correct the gla- ciological chronology. Conventional orbital tuning uses global climate proxies, such as atmospheric $\mathrm{CH}_{4}$ or $\delta^{18} \mathrm{O}$ of $\mathrm{O}_{2}$, which are matched to proximal insolation forcing (Dreyfus et al., 2007; Ruddiman and Raymo, 2003). This has brought great improvement over the glaciological chronology (e.g., EDC3 over EDC2 for the Dome C core; Parrenin et al., 2007) but the error is still up to $\sim 6 \mathrm{kyr}$ because the actual phasing between these gas proxies and orbital variations is variable.

New orbital tuning using $\mathrm{O}_{2} / \mathrm{N}_{2}$ has been developed for the Dome Fuji and Vostok cores covering 80-400 kyr BP (Kawamura et al., 2007; Suwa and Bender, 2008) (Fig. 1, A-C). $\mathrm{O}_{2} / \mathrm{N}_{2}$ in these cores is depleted relative to the atmospheric ratio because of physical fractionation during air-bubble formation at $\sim 100 \mathrm{~m}$ depth (Severinghaus and Battle, 2006). The magnitude of this depletion is controlled by the magnitude of snow metamorphism, driven by local summer insolation when the layer was originally at the surface (Bender, 2002).Although the exact mechanisms are currently not well understood, empirical evidence indicates that the $\mathrm{O}_{2} / \mathrm{N}_{2}$ variation is probably phaselocked to the local summer solstice insolation, with negligible climatic influences (Kawamura et al., 2007). The independent Dome Fuji and Vostok $\mathrm{O}_{2} / \mathrm{N}_{2}$ chronologies agree within $1 \mathrm{kyr}$, indicating robustness of the method. The accuracy of the chronology (and thus the assumption of using the solstice insolation as the target) is validated through comparison with several age markers (a volcanic ash layer and $\mathrm{CH}_{4} /$ monsoon abrupt events) whose radiometric ages are accurate to within $\sim 2 \mathrm{kyr}$ for the last $200 \mathrm{kyr}$, and which agree within $2 \mathrm{kyr}$ (Kawamura et al., 2007; Suwa and Bender, 2008; Wang et al., 2008). Suwa and Bender (2008) developed a nearly identical $\mathrm{O}_{2} / \mathrm{N}_{2}$ tuned chronology for the Vostok core (100-
$400 \mathrm{kyr}$ BP), with the addition of new $\mathrm{O}_{2} / \mathrm{N}_{2}$ data and using a slightly different method for the matching. Another local insolation proxy is air content (used for EDC3), although it gives less accurate age control (with an error of $\pm 4 \mathrm{kyr}$ ) partly because of climatic influences (Raynaud et al., 2007).

\section{Climatic implications}

The new chronology permits comparisons between parameters measured in Antarctic ice cores (such as temperature and atmospheric greenhouse gases) and orbital variations, thus providing the possibility to separate the respective contributions to past global climate and sea level changes. The 340-kyr-long Dome Fuji temperature record on the new chronology closely follows boreal summer insolation, possibly with a slight lag behind solstice insolation (Fig. 1D). Thus, the previous arguments of early Antarctic warming following the southern summer insolation to trigger northern deglaciation is not supported by the new chronology. Further, the onset of the last four Antarctic terminations are found to lag behind the minima of insolation by 2-7 kyr, and the entire duration of the warming events fit within the rising phase of June solstice insolation at $65^{\circ} \mathrm{N}$. For the last three glacial inceptions, Antarctica cooled in phase with the decrease in northern summer insolation and before significant decreases seen in $\mathrm{CO}_{2}$ and sea level (Fig. 1, D-F) curves.

The above timings are fully consistent with the view that high northern latitude summer insolation drives the 100-kyr glacial cycles by changing summertime temperature and thus long-term glacial mass balance (Raymo, 1997; Denton et al., 2006), with large amplification by albedo and $\mathrm{CO}_{2}$ feedbacks. This view is supported by the recent analysis of marine sediment data by Bintanja and van de Wal (2008), which 


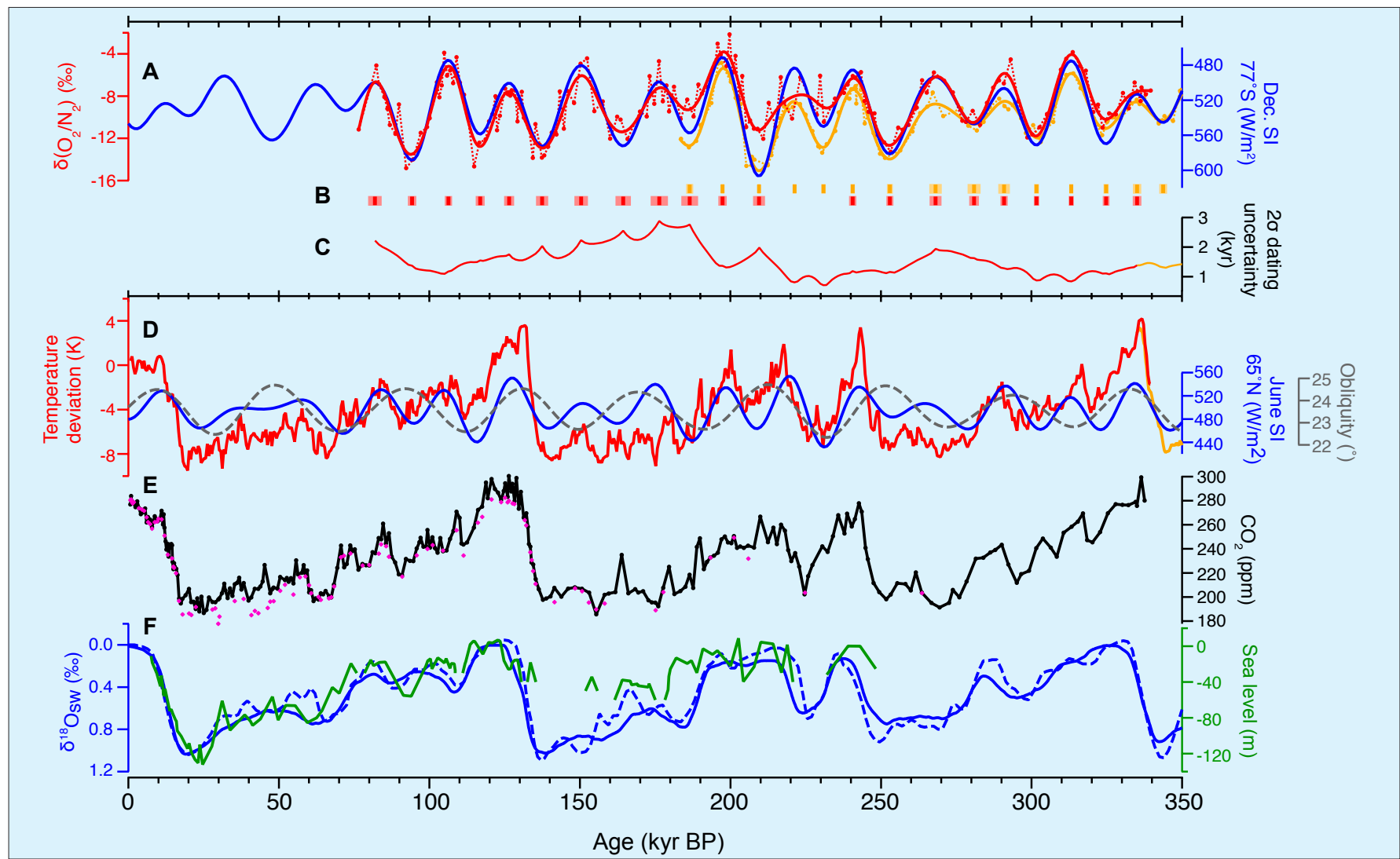

Figure 1: Accurately dated Antarctic ice core records and comparison with sea level proxies (Kawamura et al., 2007). A) Orbital tuning of O,/ $\mathrm{N}_{2}$ in the Dome Fuji (red) and Vostok (orange) cores with local summer insolation (Sl; blue). B) Tuning tie points with $2 \sigma$ error bars due to $\mathrm{O}_{2} / \mathrm{N}_{2}$ data noise. C) $2 \sigma$ dating uncertainty by combining those of the tie points and interpolation procedure. D) Dome Fuji temperature (red), Vostok temperature (orange), northern hemisphere summer insolation (Sl; blue) and obliquity (gray). E) Dome Fuji $\mathrm{CO}_{2}$ concentration by wet (black) and dry (purple) extraction. Note: wet values are too high at LGM and dry values too low in MIS 3, due to artifacts during extractions. F) Sea level reconstructions using radiometrically dated corals (green; Thompson and Goldstein, 2005) and orbitally tuned $\delta^{18} \mathrm{O}$ of seawater, based on marine sediment records through ice sheet modeling (blue solid line; Bintanja et al., 2005) and regression analyses (blue dashed line; Waelbroeck et al., 2002). Records are plotted on their own chronologies.

shows that the decrease in ice volume did not lag behind the increase of air temperature at the 100-kyr terminations after $\sim 700$ kyr BP. This suggests that the huge northern hemisphere ice sheets were actively involved in terminating the 100-kyr glacial periods.

For the last termination, the onset of sea level rise (at $19 \mathrm{kyr} \mathrm{BP}$ ) may have triggered the Antarctic warming (and $\mathrm{CO}_{2}$ rise, which is in phase with the Antarctic temperature within $1 \mathrm{kyr}$ ) through the bipolar seesaw mechanism (Clark et al., 2004). Assuming that the same mechanism worked during the older terminations, the onset of sea level rise for the older terminations is predicted to be slightly earlier than the onset of the Antarctic warming. There is an alternative view that Antarctic temperature is independent of northern climate and is controlled by the duration of the Antarctic summer, which shows a nearly identical pattern to the northern summer insolation (intensity) (Huybers and Denton, 2008). However, the tight bipolar coupling seems to apply also to orbitally driven warming events (A4 and A7 events in Blunier and Brook, 2001; see also EPICA, 2006). Thus the contribution of the local (Antarctic) orbital forcing could actually be small. A global climate modeling approach would be required to quantitatively estimate the contributions of local and distant orbital forcings to the Antarctic temperature (and $\mathrm{CO}_{2}$ ) changes.

Summer insolation intensity (June solstice, mid July, mean July, JJA average, etc.) is dominated by the precession signal, whose amplitude is modulated by eccentricity. However, the obliquity signal becomes stronger if longer periods (e.g., half-year average) or summer energy (timeintegrated insolation over the days where daily insolation exceeds a certain threshold) (Huybers, 2006) is taken into consideration. The last four terminations actually started when obliquity was relatively large (Huybers and Wunsch, 2005; Suwa and Bender, 2008). With regard to the relative importance of precession and obliquity, termination III ( 245 kyr BP) is interesting because the precession (as in northern summer insolation) and obliquity were out of phase just before the termination. Here, the pattern of temperature evolution from the termination to the next glacial inception is similar to northern summer insolation, while obliquity is decreasing from the previous peak. A longer ice core record with the $\mathrm{O}_{2} / \mathrm{N}_{2}$ chronology is certainly needed to investigate further terminations before this problem can be resolved.

\section{Outlook}

It is very important to extend the $\mathrm{O}_{2} / \mathrm{N}_{2}$ chronology further back in time. The sec- ond drilling at Dome Fuji reached $3035 \mathrm{~m}$ in depth ( 720 kyr BP according to EDC3 chronology; Motoyama, 2007) and the measurement of gas records is underway. The extended chronology will permit statistical testing of the phase stability of terminations with respect to both precession and obliquity (Huybers and Wunsch, 2005). It will also help clarify the true duration of Marine Isotope Stage 11 and how the climate evolution around this interglacial period might serve as an analog to the Holocene and future climate.

\section{Note}

Data used in this article are available from the World Data Center at www.ncdc.noaa.gov/paleo/icecore/antarctica/domefuji/domefuji.html

\section{References}

Bintanja, R. and Van De Wal, R.S.W., 2008: North American ice-sheet dynamics and the onset of 100,000-year glacial cycles, Nature, 454(7206): 869-872.

Clark, P.U., McCabe, A.M., Mix, A.C. and Weaver, A.J., 2004: Rapid rise of sea level 19,000 years ago and its global implications, Science, 304(5674): 1141-1144.

Dreyfus, G.B., et al., 2007: Anomalous flow below $2700 \mathrm{~m}$ in the EPICA Dome C ice core detected using $\delta^{18} 0$ of atmospheric oxygen measurements, Climate of the Past, 3(2): 341-353

Kawamura, K., et al., 2007: Northern Hemisphere forcing of climatic cycles in Antarctica over the past 360,000 years, Nature, 448(7156): 912-916

Suwa, M. and Bender, M.L., 2008: Chronology of the Vostok ice core constrained by $0 / \mathrm{N}$ ratios of occluded air, and its implication for the Vostok climate records, Quaternary Science Reviews, 27 1093-1106.

For full references please consult:

www.pages-igbp.org/products/newsletters/ref2009_1.html 